\title{
High Discharge Rate Lithium Ion Batteries with the Composite Cathode of LiFePO$/{ }_{4} /$ Mesocarbon Nanobead
}

\author{
Yi-Jie Gu ${ }^{1}$, Cui-Song Zeng ${ }^{1}$, Yun-Bo Chen ${ }^{2}$, Hui-Kang Wu ${ }^{1}$, Hong-Quan Liu', \\ Lin Chen ${ }^{2}$, Meng Wang ${ }^{2}$, Lin-Li Zuo ${ }^{2}$, Xiao-Wen Huang ${ }^{1}$, Xiu-Bo Liu ${ }^{3}$, \\ Jun Zhang ${ }^{1}$, Cheng $\mathrm{Lu}^{1,4}$, Yong $\mathrm{Hu}^{1}{ }^{1, a}$, Zhen Guo and Zu-Wang $\mathrm{Hu}^{1}$ \\ ${ }^{1}$ College of Materials Science and Engineering, Shandong University of Science and Technology, \\ Qingdao 266510, China \\ ${ }^{2}$ Laboratory for Laser Intelligent Manufacturing, Institute of Mechanics, Chinese Academy of \\ Sciences, Beijing 100080, China \\ ${ }^{3}$ School of Mechanical \& Electric Engineering, Soochow University, Suzhou 215021, China \\ ${ }^{4}$ Jiangsu Green Tech Energy Co., LTD, Zhenjiang 212009, China \\ a ferlove@sina.com
}

Keywords: $\mathrm{LiFePO}_{4}$; mesocarbon nanobead; 18650 cell type

\begin{abstract}
Olivine compounds $\mathrm{LiFePO}_{4}$ were prepared by the solid state reaction, and the electrochemical properties were studied with the composite cathode of $\mathrm{LiFePO}_{4} /$ mesocarbon nanobead. High discharge rate performance can be achieved with the designed composite cathode of $\mathrm{LiFePO}_{4} / \mathrm{mesocarbon}$ nanobead. According to the experiment results, batteries with the composite cathode deliver discharge capacity of $1087 \mathrm{mAh}$ for 18650 type cell at $20 \mathrm{C}$ discharge rate at room temperature. The analysis shows that the uniformity of mesocarbon nanobead around $\mathrm{LiFePO}_{4}$ can supply enough change for electron transporting, which can enhance the rate capability for $\mathrm{LiFePO}_{4}$ cathode lithium ion batteries. It is confirmed that lithium ion batteries with $\mathrm{LiFePO}_{4}$ as cathode are suitable to electric vehicle application.
\end{abstract}

\section{Introduction}

$\mathrm{LiFePO}_{4}$ has been studied intensively as a potential cathode material for rechargeable Li-ion batteries in recent years [1]. The main drawback with this material is its low electrical conductivity, which limits its electrochemical properties. Many studies on this material were devoted to overcome this problem. It has been found that reducing the particle-size, doping with metal ions and coating or blending with conducting agents such as carbons are effective methods to improve the electrical or ionic conductivities [2-4].

Our previous report showed that the excellent properties of $\mathrm{LiFePO}_{4}$ materials were obtained [5]. However, the poor rate performance limited its practical applications in areas where high power density batteries are required such as electrical vehicles and power tools. In this paper, we reported the enhanced rate performance of lithium ion batteries made of composite cathode of $\mathrm{LiFePO}_{4} /$ mesocarbon nanobead.

\section{Experimental}

$\mathrm{LiFePO}_{4}$ powder was prepared by a solid state reaction. $\mathrm{Li}_{2} \mathrm{CO}_{3}, \mathrm{FeC}_{2} \mathrm{O}_{4} \cdot 2 \mathrm{H}_{2} \mathrm{O}$ and $\mathrm{NH}_{4} \mathrm{H}_{2} \mathrm{PO}_{4}$ were dispersed into acetone and then thoroughly mixed and reground by energy ball milling. After the evaporation of acetone, the powders were calcined at $700{ }^{\circ} \mathrm{C}$ for $24 \mathrm{~h}$ in a nitrogen atmosphere. Mesocarbon nanobead samples were provided by Beijing Pines Energy Co., Ltd.

The XRD (X-ray diffraction) patterns of the calcined powder were collected for structural analysis. The XRD data were obtained over an angular $2 \theta$ range from 10 to $70^{\circ}$ with a step size of $0.02^{\circ}$ and a constant counting time of 1 second per step. Powder morphologies were observed by SEM (scanning electron microscope). 
92\% $\mathrm{LiFePO}_{4}$ powder, 5\%MCMB, 3\% $\%$ PVF (poly vinylidene fluoride) binder and NMP (N-methylpyrrolidone) organic solvent were blend together in a high-speed mixer. The viscous slurry was then coated onto an aluminum foil current-collector and dried at $120{ }^{\circ} \mathrm{C}$ under vacuum for $24 \mathrm{~h}$. The resulting electrode was used as a cathode. The cell was assembled using the above mentioned cathode, the anode made from natural graphite and PVDF binder, the separator of Celgard 2400 microporous membrane, and electrolyte solution of 1.2 $\mathrm{MLiPF}_{6}$ in a mixture solvents of EC (ethylene carbonate), PC (propylene carbonate) and DMC (dimethyl carbonate).

\section{Results and Discussion}

Fig. 1 shows the XRD pattern of the mesocarbon nanobead powder. The mesocarbon nanobead powder has a strong (002) diffraction line. The degree of graphitization was estimated by g-factor, which is defined as $(0.3440-$ $\left.d_{002}\right) /(0.3440-0.3354)$ [6]. The content of graphitization is $48.8 \%$. The morphology observed by SEM is shown in Fig. 2. The mesocarbon nanobead powder has a spherical shape and an average particle size of 300-600nm.

At the low discharge rate $(1100 \mathrm{~mA})$, $1130 \mathrm{mAh}$ were delivered for cell type 18650 at 50th cycle.

Fig. 3 shows the cycle properties of cell type 18650 with $\mathrm{LiFePO}_{4}$ as cathode. Cells were

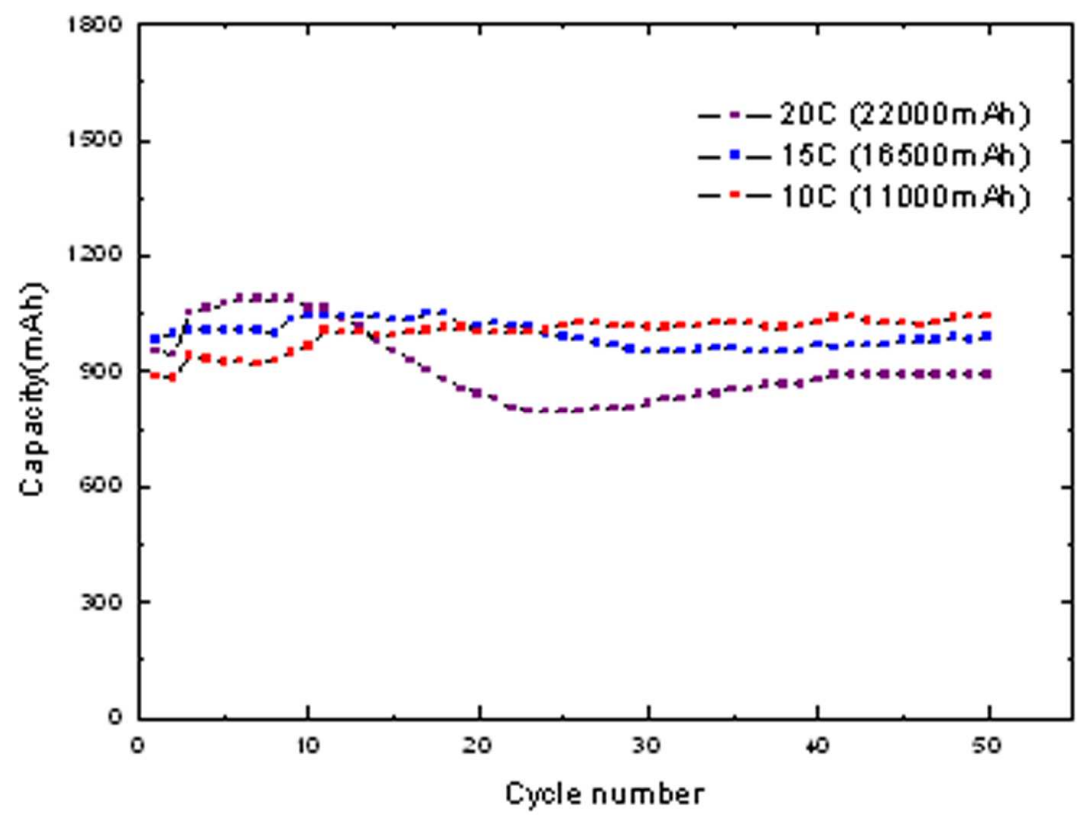

Fig. 3. Discharge capacity profiles for a cell prepared with the composite cathode of $\mathrm{LiFePO}_{4} /$ mesocarbon nanobead, 10C (11000mAh), 15C (16500mAh) and 20C (22000mAh) 
discharged with different electrical currents ranging from 10 to 20C. The cells are cycled between voltages range of $2.00-3.65 \mathrm{~V}$. All cells were charged with the same current $(1 \mathrm{C}, 1100 \mathrm{~mA})$. The discharge capacity is $1045 \mathrm{mAh}$ at the $50^{\text {th }}$ cycle at $10 \mathrm{C}$ discharge rate. A maximum discharge capacity of $1054 \mathrm{mAh}$ was obtained at $18^{\text {th }}$ cycle at $15 \mathrm{C}$ discharge rate. A maximum discharge capacity of $1087 \mathrm{mAh}$ was achieved at the $6^{\text {th }}$ cycle under the $20 \mathrm{C}$ discharge rate. Many works reported that lithium battery use $\mathrm{LiFePO}_{4}$ as cathode materials to improve rate performance. A good voltage plateau remained above $3 \mathrm{~V}$ even at the $10 \mathrm{C}$ rate [7]. The synthesized LiFePO4 exhibits a material utilization of more than $59 \%$ at a rate as high as $5 \mathrm{C}$ [8].

The enhanced conductivity and the excellent high rate performance of the composite cathode of $\mathrm{LiFePO}_{4} /$ mesocarbon nanobead can be explained in Fig. 4. The mesocarbon nanobead provided the conducting net among $\mathrm{LiFePO}_{4}$ particles. The uniformity of mesocarbon nanobead around $\mathrm{LiFePO}_{4}$ can supply enough change for electron transporting, which can enhance the rate capability for $\mathrm{LiFePO}_{4}$ cathode lithium ion batteries.

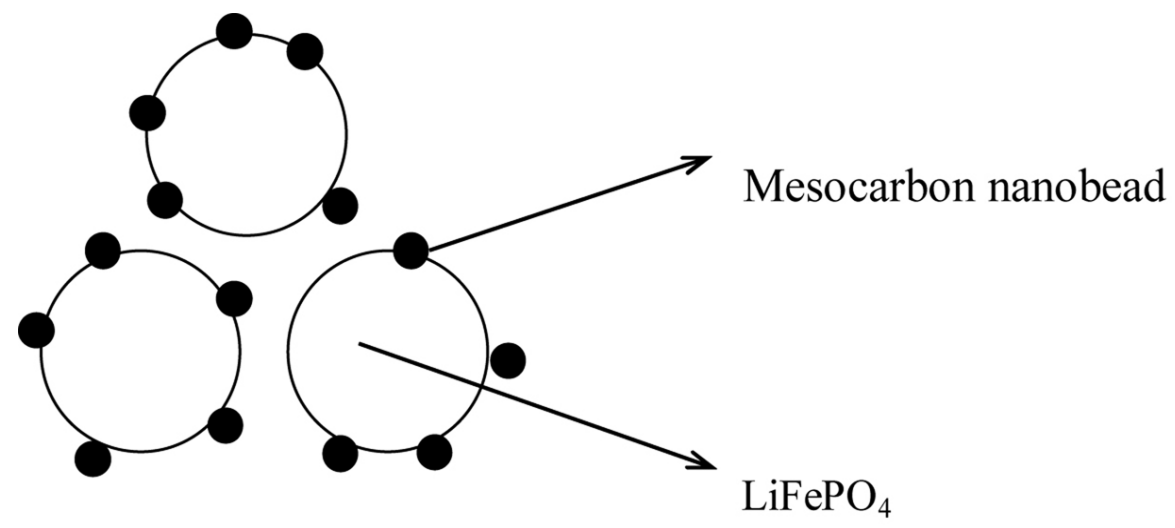

Fig. 4. A sketch indicating the mechanism for high rate capability

\section{Conclusion}

High rate performance can be achieved with the designed composite cathode of $\mathrm{LiFePO}_{4} / \mathrm{mesocarbon}$ nanobead (The discharge capacity is $1087 \mathrm{mAh}$ at the $20 \mathrm{C}$ discharge rate for 18650 cell), which makes $\mathrm{LiFePO}_{4}$ based lithium ion battery an excellent candidate for electric vehicle application.

\section{Acknowledgements}

This work was financially supported by 863 program (Grant No.2009AA11A106), Jiangsu Major Scientific and Technological Achievements Implementation Funds (Grant No.200910) and Jiangsu Provincial Natural Science Foundation (BK2009134).

\section{References}

[1] A. Padhi, K. Nanjundaswamy and J. Goodenough: J. Electrochem. Soc. Vol. 144 (1997), p.1188.

[2] A.Yamada, S.C. Chung and K. Hinokuma: J. Electrochem. Soc. Vol.148(2001), p.224.

[3] S.Y. Chung, J.T. Blocking and Y.M. Chiang: Nat. Mater. Vol. 1(2002), p.123.

[4] H. Huang, S.C. Yin and L.F. Nazar: Electrochem. Solid-State Lett. Vol. 4(2001), p.170.

[5] Y.-J. Gu, C.-S. Zeng, H.-K. Wu, et al.: Mater. Lett. Vol. 61(2007), p.4700.

[6] C.W. Park, S.-H. Yoon and S. M. Oh: Carbon. Vol. 38(2000), p.1261.

[7] Y. Wang, J. Wang, J. Yang, et al.: Adv. Funct. Mater. Vol.16(2006), p.2135.

[8] H.M. Xie, R.S. Wang, J.R. Ying, et al: Adv. Mater. Vol. 18(2006), p.2609. 
Testing and Evaluation of Inorganic Materials I

10.4028/www.scientific.net/AMR.177

High Discharge Rate Lithium Ion Batteries with the Composite Cathode of $\mathrm{LiFePO}_{4} / \mathrm{Mesocarbon}$ Nanobead

10.4028/www.scientific.net/AMR.177.208

\section{DOI References}

[1] A. Padhi, K. Nanjundaswamy and J. Goodenough: J. Electrochem. Soc. Vol. 144 (1997), p.1188. doi:10.1149/1.1837571 